\title{
A Moralidade do desenvolvimento: notas para uma tipologia do dominador
}

\author{
Bernardo Oliveira*
}

Oh, mar! Oh, noite! Vocês são maus instrutores! Ensinam o ser humano a parar de ser humano! Deve ele entregar-se a vocês? Deve tornar-se, como são agora, pálido, brilhante, mudo, imenso, repousando em si mesmo? Elevado sobre si mesmo?

Aurora, § 423

Resumo: Na medida em que a moralidade kantiana se instaura a partir do reconhecimento das condições universais para o bem estar geral, o filocrata kantiano se distingue pela impessoalidade de suas ações, pela obediência à norma e a introjeção da "responsabilidade", em vistas de privilegiar a universalidade como princípio regulador das ações e dos valores. Considerando o niilismo como "doença da vontade" ocasionada pela ausência de metas, mas também como a convicção de que a realidade é desprovida de sentido objetivo, o tipo-dominador nietzschiano deve, ao contrário, afirmar os traços singulares de sua personalidade, a fim de operar o elemento dinâmico da história. Em vistas de superar o niilismo reativo, a tipologia do dominador em Nietzsche indicará uma outra possibilidade de filocracia, transfiguradora, imprevisível e de caráter não-normativo.

Palavras-Chave: Nietzsche, Kant, tipologia, moral.

* Professor da Universidade Federal do Rio de Janeiro (UFRJ), Rio de Janeiro, RJ, Brasil.

Correio eletrônico: bernardo.oliveira@gmail.com 
Oliveira, B.

\section{Tipologia e "filocracia"1}

Duas tipologias da individuação moral e da virtude residem no cerne do pensamento político de Kant e Nietzsche. Situadas em contextos e horizontes completamente diferentes, acabam por travar grandes batalhas ainda hoje no interior de questões caras aos debates éticos e políticos contemporâneos. Ambos se impuseram a tarefa de levar estas tipologias ao limite, delineando inclusive as condições de possibilidade do tipo-dominador, aquele sobre o qual recairia a tarefa de produzir a paz perpétua ou a transvaloração de todos os valores. No caso de Nietzsche, uma tipologia descreve sua rota em franca correlação com a imprevisibilidade da ação de homens concretos, o lastro de obras e feitos de grandes homens — de forma que, me parece, a pergunta adequada não seria pelos seus requisitos, mas por sua identidade: quem é hoje o tipo-moral nietzschiano a encarnar o gosto pelo domínio? E se, como uma evidente provocação, fizéssemos a mesma pergunta a Kant: quem é o ser racional kantiano nos dias de hoje? Não teríamos que necessariamente oscilar entre dois tipos, a saber: os políticos e burocratas eichmannianos ou o

1 As palavras Tipologia [Typenlehre] e Morfologia [Morphologie] são utilizadas por Nietzsche em momentos fundamentais. Em JGB/BM 186 (KSA 5.105), Nietzsche relaciona a tipologia com a necessidade de coletar e ordenar "um imenso domínio de delicadas diferenças e sentimentos de valor", numa clara alusão às particularidades inerentes à variedade de tipos humanos. Em JGB/ BM, 23 (KSA 5.38), Nietzsche se refere à "morfologia e teoria da evolução da vontade de potência" como uma psicologia que "desce às profundezas", isto é, que busca na constituição complexa da cultura e dos indivíduos as reais motivações dos diversos modos de vida. Com a palavra "filocracia", pretendemos indicar as inclinações tipológicas que se desenvolvem como uma moral do domínio e da "grandeza cultural". Convém, no entanto, chamar a atenção para o trecho a seguir: "A noção de tipo é uma das noções mais importantes do pensamento de Nietzsche. Sobre ela, assim como sobre a noção de valor, se estabelece o problema da cultura, que constituirá doravante o centro organizador da reflexão filosófica. O tipo designa o exemplo particular capaz de representar melhor todos os casos que compartilham características comuns, sem que sejam negadas suas possíveis diferenças. Este conceito é concebido essencialmente como plural e refere-se à necessidade de estudar os diferentes tipos humanos, quer dizer, as múltiplas 'possibilidade(s) de vida' evidenciadas pela história humana, e que caracterizam formas de pensar, de agir, e, sobretudo, dos valores particulares. (...) O tipo, se opõe às abstrações idealistas, não se confunde porém com o individual ou o singular uma vez que envolve a identificação de características comuns a indivíduos ou culturas diversas." (C. Denat \& P. Wotling, 2013, p. 257-262)

162 | Cad. Nietzsche, Guarulhos/Porto Seguro, v.39, n.2, p. 161-186, maio/agosto, 2018. 
A Moralidade do Desenvolvimento: Notas para uma tipologia...

homem de bem, a figura nietzschiana do último homem, ambos zelosos cumpridores de seus deveres? Nietzsche é claro em seu diagnóstico a respeito da crítica kantiana: Kant não considerou a razão enquanto um valor que, com múltiplos objetivos, passou por uma série de apropriações e transformações, porque a convicção o manteve preso ao sono dogmático, o que por certo evitaria qualquer possibilidade de pensá-la como um dispositivo inato na constituição do humano. Kersting, no entanto, assevera que o pensamento moral e político de Kant, apesar de seu substrato apriorístico, opera conforme determinadas condições, podendo inclusive amoldar-se a elas:

(...) a filosofia política de Kant também reflete cuidadosamente as condições empíricas para a realização das normas da teoria racional do direito e desenvolve um surpreendente pragmatismo, envolvendo-se com relações de poder político conforme são dadas, a fim de descobrir e explorar as possibilidades de mudança sem a necessidade do uso da força e voltada para a realização dos princípios. ${ }^{2}$

Por que Nietzsche, então, insiste na pergunta: quem deseja a razão (ou, ainda, a verdade) e por que é desejável reconhecê-la como um a priori? Os termos das disputas políticas podem se alterar, mas Kant deposita sobre a sua tipologia moral os dispositivos que tornariam os indivíduos capazes de agir sob princípios em quaisquer épocas ou situações, ainda que os resultados possam variar conforme o jogo de forças. É possível entrever na elaboração do imperativo categórico os elementos citados por Nietzsche na constituição do tipo sacerdotal: a impessoalidade do pensamento gregário ${ }^{3}$; a cisão entre mundo verdadeiro e mundo aparente representado pela introjeção da lei; a

2 Kersting, 1992, p. 343.

3 "Dizer que a lei moral última deve ser universal corresponde à afirmação de que toda lei moral particular deve ser objetiva e impessoal, que não pode ser determinada apenas por meus desejos e que deve ser imparcial entre uma pessoa e outra. Certamente não há nada para criticar nesta ideia, mesmo se acreditarmos que temos uma intuição direta de uma qualidade não analisável [unanalysable] de bondade (ou obrigação) e uma intuição direta dos tipos de ação nos quais uma qualidade não analisável é necessariamente manifestada" (Paton, 1953, p. 136).

Cad. Nietzsche, Guarulhos/Porto Seguro, v.39, n.2, p. 161-186, maio/agosto, 2018. 
Oliveira, B.

equivalência entre duas ações, a introdução da razão como elemento abstrato e regulatório - fundamento cuja forma Nietzsche percebe como sucedâneo do pensamento teológico. Sob as lentes da semiótica dos afetos nietzschiana, a tipologia moral de Kant se configura como um dos sintomas mais evidentes do niilismo moderno, ao prefigurar um mundo coordenado por sábios e burocratas, aptos a decodificar e cumprir determinadas normas em função de uma lei maior.

Ainda sem considerar o valor de afirmações como "existe em nós um imperativo categórico", sempre se pode perguntar: o que diz uma tal afirmação sobre aquele que a faz? Existem morais que pretendem justificar perante os outros o seu autor; outras morais pretendem acalmá-lo e deixá-lo contente consigo mesmo; (...) talvez Kant entre eles, dão a entender com sua moral: "o que merece respeito em mim é que sou capaz de obedecer — e com vocês não será diferente!" — em suma, também as morais não passam de uma semiótica dos afetos. (JGB/BM, 187, KSA 5.107)

Para Nietzsche, o pensamento moral de Kant estimula a supressão da singularidade individual, constrangendo o poder multiforme dos conflitos e solapando o elemento dinâmico da cultura em favor do nivelamento cultural e da obediência. Se o conteúdo apriorístico da moral kantiana supõe o reconhecimento acrítico da "causalidade da vontade", é justamente no questionamento deste a priori - a razão edificada como um princípio de realidade a priori - que Nietzsche concentra seus ataques a Kant. "Deus está morto", contudo, segundo Nietzsche, Kant o substituiu por uma "responsabilidade", cujo critério de valoração permanece abstrato e impessoal, independente das condições políticas e da necessidade de se reproduzir determinados comportamentos que seriam, nas palavras de Kant, fruto de uma boa vontade em si mesma. Querer o bem de todos ou da maioria implica em revestir sua ação de "universalidade", pretendendo que sua "máxima se torne uma lei universal." Contradizendo essa perspectiva,

4 Kant, 1974, p. 223.

164 | Cad. Nietzsche, Guarulhos/Porto Seguro, v.39, n.2, p. 161-186, maio/agosto, 2018. 
A Moralidade do Desenvolvimento: Notas para uma tipologia...

o que se torna "imperativo" na filosofia moral nietzschiana opera em sentido inverso:

Como? Você admira o imperativo categórico em você? Essa "firmeza" do que é chamado seu juízo moral? Essa "incondicionalidade" do sentimento de que "nisso todos têm de julgar como eu"? Admire antes seu egoísmo nisso! Pois egoísmo é sentir o próprio juízo como uma lei universal; e novamente um egoísmo cego, estreito e modesto, porque mostra que você ainda não descobriu a si mesmo, ainda não criou para si um ideal próprio, bastante próprio - pois ele não poderia jamais ser o de um outro, e muito menos o de todos, todos! — Quem ainda julga que "assim deveriam agir todos nesse caso", não chegou a andar cinco passos no autoconhecimento (...) (FW/GC, 335, KSA 3.560).

Porque busca captar o processo de constituição do niilismo moderno, a crítica nietzschiana acaba por indicar uma outra direção vinculada à necessidade de fomentar formas de vida e de pensamento que façam frente ao processo de nivelamento cultural e rebaixamento do tipo-homem e se imponham tanto por sua singularidade, como pela riqueza de seus antagonismos. Considerando provisoriamente o niilismo como a convicção de que a vida não possui um sentido objetivo e a tipologia do dominador como um dispositivo de superação do niilismo, o tipo-dominador nietzschiano deve, portanto, operar o elemento dinâmico da história, o que implica em uma outra possibilidade de filocracia, transfiguradora, imprevisível e de caráter não-normativo.

\section{O filocrata kantiano}

Em Kant, pode-se descrever brevemente uma autêntica batalha que define a tipologia do aspirante à intelecção do "reino dos fins em si mesmos": de um lado, a força descomunal de suas "necessidades e inclinações" - em outras palavras, sua "felicidade"5; de outro, a

5 Kant, 1974, p. 212.

Cad. Nietzsche, Guarulhos/Porto Seguro, v.39, n.2, p. 161-186, maio/agosto, 2018. 
Oliveira, B.

inexorável submissão aos "mandamentos do dever". É possível que a notória crítica nietzschiana ao caráter impessoal do imperativo categórico tenha se deixado levar por uma caricatura, que, contudo, acomodava-se ao projeto de crítica dos valores. A batalha moral que se trava no interior do ser racional indica que o tipo-dominador kantiano é edificado a partir de uma referência contrária à máxima pindárica: ao invés de "torna-se aquilo que é", investindo todas as suas forças em intensificar um processo de expansão da singularidade do caráter, o ser racional kantiano deve, através de uma escolha particular, obedecer a uma lei superior. Qual o sentido de uma tipologia da individuação moral que compatibiliza as noções de contingência e liberdade, fazendo-as, contudo, travar uma verdadeira guerra no âmago do indivíduo? Para atingir o máximo de sua potência, o tipo-dominador, tanto em Kant, como em Nietzsche, deve passar por um processo de auto-formação contínua. Em ambos os casos, pode-se dizer que este encaminhamento auto-formativo constitui o elemento central na educação do tipo-dominador. Contudo, é possível diferenciá-las ao nível de seus pressupostos? Kant, na Fundamentação da Metafísica dos Costumes, nos fala de uma "obrigação":

Cada coisa da natureza opera segundo leis. Só um ente racional tem a faculdade de agir segundo a representação de leis, isto é, segundo princípios, ou uma vontade. Visto que para a dedução de ações de leis requer-se razão, a vontade não é senão uma razão prática. Se a razão determina inevitavelmente a vontade, então as ações de um tal ente, conhecidas como objetivamente necessárias [são também subjetivamente necessárias], isto é, a vontade é uma faculdade de escolher somente aquilo que a razão, independentemente das inclinações, conhece como praticamente necessário, isto é, como bom. (...) A representação de um princípio objetivo, na medida em que é obrigatória para uma vontade, chama-se mandamento [da razão], e a fórmula do mandamento chama-se imperativo. (...) $\mathrm{O}$ imperativo categórico seria aquele que representa uma ação como objetivamente necessária por si mesma, sem relação com um outro fim. ${ }^{6}$

6 Kant, 1974, p. 217-218.

166 | Cad. Nietzsche, Guarulhos/Porto Seguro, v.39, n.2, p. 161-186, maio/agosto, 2018. 
A Moralidade do Desenvolvimento: Notas para uma tipologia...

A atitude fundamental de Kant é um reconhecimento inquestionado da veracidade de seu problema, que recai sobre sua tipologia da virtude. Disso resulta a articulação meticulosa de definições e preceitos morais de ordem metafísica, considerados de antemão verazes e desejáveis: a razão, o imperativo, a intuição, a conduta "moral", a liberdade como responsabilidade etc. A Kant interessam também as leis do nosso pensamento, através das quais a pluralidade do devir pode ser suprimida e regularizada. De forma análoga ao modo como os cristãos instauram e creem em um "outro mundo" para fins compensatórios, Kant suprime a pluralidade da cultura em favor de uma suposta unidade do dispositivo moral da ação. Fundada num sistema que busca, de um lado, separar a razão do regime afetivo, e, por outro, conferir à razão o papel de organizador e regulador da ordem, a crítica kantiana se mantém no plano dos valores incondicionados. Por seu turno, ao contrapor Goethe a Kant, Nietzsche observa que o primeiro teria combatido "a separação de razão, sensualidade, sentimento, vontade..." (GD/CI, "Incursões de um extemporâneo", 49, KSA 6.151), enquanto o segundo teria buscado separá-los meticulosamente. Também pergunta pela verdade enquanto um valor imanente a certas dinâmicas culturais, interpretando o fenômeno moral kantiano como a generalização de uma "concepção do dever em geral". ${ }^{7}$ Nietzsche se pergunta com que propósito se estabelece uma instância legisladora superior, supostamente independente dos afetos, senão para justificar o cumprimento desta lei. Ele é, por vezes, equívoco na definição de uma tipologia moral, porque não reveste sua crítica com a estabilidade fornecida pelo aparato teórico da razão filosófica, científica ou econômica, mas busca na superação das formas de vida modernas a base para outras

7 Cf. AC/AC, 11, KSA 6.177: "As mais profundas leis da conservação e do crescimento exigem o oposto: que cada qual invente sua virtude, seu imperativo categórico. Um povo perece quando confunde seu dever com a concepção do dever em geral. (...) O que destrói mais rapidamente do que trabalhar, pensar, sentir sem necessidade interna, sem uma profunda escolha pessoal, sem prazer? como autômato do 'dever'? É a própria receita da décadence, até mesmo do idiotismo..."

Cad. Nietzsche, Guarulhos/Porto Seguro, v.39, n.2, p. 161-186, maio/agosto, 2018. 
Oliveira, B.

formas de vida. Ora, se a crítica nietzschiana tem por objeto a moral como expressão das formas de vida, isto se dá, sobretudo, em favor de um desenvolvimento efetivo das potencialidades inexploradas em direção à superação do niilismo e a "estados mais completos de humanização." A crítica nietzschiana à filosofia moral kantiana se dá, então, nos termos de uma inobservância estratégica, que produz a manutenção da responsabilidade e da obediência:

Os trabalhadores filosóficos formados segundo o nobre modelo de Kant e Hegel têm de estabelecer e colocar em fórmulas, seja no reino do lógico, do político (moral) ou do artístico, algum vasto corpo de valorações — isto é, anteriores determinações, criações de valores, que se tornaram dominantes e por um tempo foram denominadas "verdades." (JGB/BM, 211, KSA 5.144)

"Anteriores determinações" que se exprimem como obediência ou acomodação a uma estrutura de poder que, inquestionada, prevalece. Se há uma forma de se conceber a influência sacerdotal no horizonte constitutivo da civilização ocidental, esta se dá a partir da divinização de uma outra existência, na qual seus valores e metas seriam realizáveis - uma existência fictícia. Os teólogos, sacerdotes e "trabalhadores filosóficos", isto é, os "tipos superiores" que se destacaram neste processo, não souberam compreender o "sentido de necessidade" (WB/Co. Ext. IV, 1, KSA 1.431) e não produziram as condições necessárias para conferir um sentido positivo à vida da comunidade. Nestas condições, "a moral, não é mais expressão das condições de vida e crescimento de um povo, não mais seu mais básico instinto de vida, e sim tornada abstrata, antítese da vida" (AC/AC, 25. KSA 6.193)

8 Candido, 1983.

168 | Cad. Nietzsche, Guarulhos/Porto Seguro, v.39, n.2, p. 161-186, maio/agosto, 2018. 
A Moralidade do Desenvolvimento: Notas para uma tipologia...

\section{Niilismo: metas e valores}

O principal objetivo do projeto filosófico de Nietzsche é investigar as possibilidades de superação do niilismo, que vem a ser preliminarmente a convicção de que a vida não tem sentido objetivo ou de que, mediante nossos valores, não somos dignos de vivê-la. Niilismo como ausência de propósitos e objetivos permanentes, disposição para a vida marcada pelos sentimentos de "desorientação" e "desespero" em decorrência da "morte de deus", considerada como o elemento genealógico que evidencia o niilismo, mas também qualquer conjunto de valores que não se perceba realizável neste mundo. Niilismo, portanto, como a crença de que a existência não tem sentido. Os valores morais não se realizam e, por não se realizarem, diminuem a potência daquele que compartilha e crê nos mesmos. O que seria, então, uma vida repleta de sentido, se todos os nossos valores foram desvalorizados, e não somente os "altos valores"? Dar à vida um sentido é para Nietzsche algo natural, na medida em que se pode considerar empiricamente plausível que as pessoas careçam de uma razão, ou de uma atividade para viverem. Portanto, niilismo é a convicção de que a vida não faz sentido, não somente porque nossas metas são irrealizáveis, mas porque a vida em geral não possui nexo. Então, para o niilista, não faz sentido também investir em suas próprias metas.

Mas Nietzsche, Reginster observa, afirma que esta compreensão concerne às coisas que têm valor, não ao valor mesmo. Isto é: os cristãos creem que seus mais altos valores serão realizados em alguma instância "além", enquanto o niilista não crê de forma alguma que haja um mundo no qual ele seria capaz de realizar seus valores. Para ele, ao contrário do cristão, não há lugar onde seus valores seriam realizados. Nesse sentido, o niilista e o pessimista compartilham a visão de que "o mundo é algo que racionalmente não deveria existir"

9 Reginster, 2006, p. 33. 
Oliveira, B.

(Nachlass/FP, 11 [61], 1887-1888, KSA 13.30). Não se trata de uma consideração em relação ao valor, mas à sua capacidade de realização. O niilismo que Nietzsche pretende denunciar como um elemento constituinte da modernidade, geralmente se atrela à segunda possibilidade. De uma forma geral, a vida não tem sentido, ainda que, entre comentadores, seja tema de debate a perspectiva segundo a qual Nietzsche recuse os valores morais enquanto "realidades". Uma vida que inspira grandeza há de se propor metas a cumprir, feitos a serem realizados, atribuindo valores a essas realizações. Na perspectiva kantiana, metas e valores tendem a ser confundidos como uma só e mesma inclinação ao dever, a ação em si e a motivação da ação. $\mathrm{O}$ valor, então, se transforma em algo "bom" ou "ruim" por si só, como se "o valor do valor" proviesse de alguma instância externa à ação. A noção de Democracia, por exemplo, é uma ideia ordinariamente concebida como valor em si, mas trata-se de um estado de coisas a ser efetuado. Entretanto, em Nietzsche, é preciso separar metas e valores. Ele diz que uma vida é digna (isto é, tem sentido) somente se possui metas ou encontra sentido nas metas que propõe. A meta está ligada a um estado de coisas e o valor é algo atribuído posteriormente. Por isso, de uma forma geral, a vida não tem sentido, e de uma forma particular, o indivíduo e/ou a comunidade conferem sentido à vida através de suas ações ou metas.

Uma meta torna digna a vida se inspira o agente a perseverar na existência. Então, duas coisas são importantes: se o agente estima o valor da meta e se concebe a realização da meta, independente de elementos que façam a mediação entre a vontade e a razão. De forma que o niilismo possui duas fontes: uma desvalorização das metas sobre as quais se fundam o sentido das nossas vidas e a convicção de que essas metas são irrealizáveis. Consequentemente, a estima do agente pelo valor da meta pode ser alterada e as condições de realização podem simplesmente não existir. Metas que não possuem capacidade de realização não inspiram a continuar a viver. Ao mesmo

$170 \mid$ Cad. Nietzsche, Guarulhos/Porto Seguro, v.39, n.2, p. 161-186, maio/agosto, 2018. 
A Moralidade do Desenvolvimento: Notas para uma tipologia...

tempo, isso não quer dizer que elas perdem o valor no ponto de vista do agente: "Ao contrário, o agente deve permanecer comprometido com seus valores irrealizáveis, mas sua vida perde o sentido."10 Uma tipologia do dominador em Nietzsche, portanto, remeteria necessariamente à constituição e fortalecimento de uma vontade, de modo a estabelecer metas realizáveis neste mundo possível, superar a desorientação e o desespero niilista, e afirmar o caráter singular e sua influência sobre o corpo de valores da comunidade.

\section{A moralidade do desenvolvimento}

Danto afirmou categoricamente que Nietzsche era um "niilista" no livro Nietzsche as philosopher ${ }^{11}$. Em seguida, Richard Schacht observou que poucos são os trechos onde Nietzsche de fato afirma ser um niilista, ou identifica sua filosofia como niilista, geralmente nos manuscritos não publicados. Schacht acrescenta que em Ecce Homo, Nietzsche, sim, se identifica como um "imoralista" - o que também é motivo de objeção, já que Nietzsche "não repudia todas as formas de moralidade, mas apenas algumas, associadas primeiramente à tradição judaico-cristã."12 Nas passagens usadas por Danto, Nietzsche se autoproclama "o primeiro niilista perfeito da Europa". Schacht recorre, então, à célebre frase: "Um niilista é um homem que julga que o mundo tal como é não deveria existir, e que o mundo tal como deveria ser não existe." (Nachlass/FP, 9 [60], 1887, KSA 12.364) Face a esta e outras citações, Schacht

10 Reginster, 2006, p. 25.

11 “'Às vezes', diz Danto, Nietzsche falou de sua filosofia como niilismo. Isso é verdade? E é verdade, além disso, que Nietzsche faz 'reivindicações desenfreadas em favor desse extremo niilismo'?" (Schacht, 1973, 58).

12 Schacht, 1973, p. 60. Cf. também a concepção segundo a qual a crítica de Nietzsche à moral pode ser interpretada como uma crítica à unilateralidade moral do Ocidente, em Tongeren, 2012, p. 104: "De fato, a crítica de Nietzsche à unilateralidade moral se dirige, em primeira instância, contra uma determinada moral que atualmente é dominante na Europa: a moral de rebanho ou cristã."

Cad. Nietzsche, Guarulhos/Porto Seguro, v.39, n.2, p. 161-186, maio/agosto, 2018. 
Oliveira, B.

conclui que o Niilismo para o filósofo é uma derivação histórica da decadénce, fenômeno contra o qual ele reage e que considera como algo que deve ser superado. Como ele seria um niilista, então? Como diversos autores chegaram a essa conclusão tão contrária ao que Nietzsche escreveu e pensou? Schacht sugere que a ambivalência do enfoque que Nietzsche empregava ao analisar o tema pode ter estimulado contrassensos, já que ora ele situa como um fenômeno catastrófico (e inevitável), ora como "um bom sinal". 13 "Niilismo. Ele é ambíguo: A. Niilismo como um sinal do aumento do poder do espírito: o niilismo ativo. B. Niilismo como declínio e diminuição do poder do espírito: niilismo passivo". (Nachlass/FP, 9[35], Outono de 1887, KSA 12.350) ${ }^{14}$

Pode-se ainda cogitar o Niilismo como uma "transição patológica" (Nachlass/FP, 9[35], 1887, KSA 12.350) - patológico por conta da generalização do pensamento niilista. Schacht afirma que "a ilegitimidade lógica da generalização, por si só, não serve para estabelecer que outra interpretação do mundo é possível, de forma que o sentido do que Nietzsche quer nos dizer permanece por ser visto" 15 . No entanto, é importante notar que nesta "profecia", a palavra do filósofo não implica em sua adesão, nem afirma que o niilismo é uma posição final e correta. Niilismo como epílogo ou prólogo? Os dois tipos são "transitivos", mas apenas um o é em sentido estritamente positivo. Ambos indicam que a composição moral judaico-cristã que amparava as relações entre certos grupamentos humanos se quebrou, entretanto o enfoque é diferente. $O$ reconhecimento da impossibilidade de realizar seus valores faz com que o niilista condene o mundo e considere o mundo e sua vida sem sentido. É o desespero como

13 Schacht, 1973, p. 62.

14 No original: "Nihilismus. Er ist zweideutig: A. Nihilismus als Zeichen der gesteigerten Macht des Geistes: der aktive Nihilismus. B. Nihilismus als Niedergang und Rückgang der Macht des Geistes: der passive Nihilismus."

15 Schacht, 1973, p. 63.

172 | Cad. Nietzsche, Guarulhos/Porto Seguro, v.39, n.2, p. 161-186, maio/agosto, 2018. 
A Moralidade do Desenvolvimento: Notas para uma tipologia...

contrapartida psicológica natural que aflora e faz com que o niilista passe a não querer mais compreender o mundo. Contudo Nietzsche pode ser considerado um niilista em pelo menos um sentido: ele entende que o mundo é, de fato, "desprovido de valor", mas isso não esgota, nem constrange, a capacidade de operar sobre o mundo nem implica em considerá-lo necessariamente incompreensível. Nietzsche considera o niilismo "o perigo dos perigos"16 por elidir a antiga visão de mundo, gerando uma crise de valores que não assegura a criação de uma nova visão de mundo. Ele assume que é necessário ter uma visão de mundo, concebida sob os critérios de uma "natureza afirmativa" - isto é, livre de todo incondicionado. Schacht se propõe, então, não só a desmentir o veredito de Danto, de que Nietzsche seria um niilista e que sua filosofia, um contraponto ao niilismo, como também contradizer a perspectiva segundo a qual Nietzsche afirmaria "não ter nada a dizer sobre a realidade." Segundo Schacht, Nietzsche não é um niilista, se se concebe o niilismo como a ideia de que "nem o mundo, nem os valores são de tal forma que qualquer coisa positiva e objetivamente verdadeira pode ser dita a respeito deles". ${ }^{17}$. Há, portanto, uma tensão entre realismo e irrealismo na construção da ideia de niilismo em Nietzsche. Schacht argumenta que Nietzsche acredita em uma dimensão da verdade irredutível à verdade platônica, cristã, metafísica, isto é, as que vingaram até agora no horizonte constitutivo da história moderna. Existiria um conteúdo de "verdade" em Nietzsche a respeito do mundo e da natureza do homem que não se apresenta propriamente como "descoberta" (pois não sendo "objetiva", não está oculta como sentido prévio), mas que ele percebe, estuda, avalia. Schacht se pergunta o que é isso que ele descobre e chama repetidamente de "a verdade". "Esse mundo é vontade de potência. - e nada mais. E vocês mesmos são vontades de potência" (Nachlass/FP, 38[12], 1885, KSA 11.610). Nietzsche

16 Schacht, 1973, p. 64.

17 Schacht, 1973, p. 66.

Cad. Nietzsche, Guarulhos/Porto Seguro, v.39, n.2, p. 161-186, maio/agosto, 2018. 
Oliveira, B.

considera essa "verdade" tão válida quanto as outras - platônica, a cristã, a kantiana, a hegeliana, a mecanicista - que por sua vez são válidas, contudo falsas, enquanto a sua é verdadeira. Nietzsche está comprometido com uma visão de mundo metafísica pouco ortodoxa, mas ele não é definitivamente um "niilista metafísico". Ele pode ser considerado um niilista axiológico, no sentido de que crê na inexistência de base objetiva para determinações de valores. ${ }^{18} \mathrm{E}$ quais seriam para Nietzsche esses valores absolutos, de onde derivariam todos os outros?

A melhoria qualitativa e quantitativa da vida, e, em particular, daquele a que ele frequentemente se refere como o tipo-homem, culminando com "o ideal de união de uma superioridade espiritual com o bem-estar e um excesso de força" (Nachlass/FP, 35[28], maio-julho, 1885). ${ }^{19}$

Para Nietzsche, este "valor absoluto" não é ordenado sob a força de um imperativo imaginário, mas também não se reduz a uma mera convenção, se não que está na própria natureza das coisas. Este valor é próprio e essencial à vida e se chama Vontade de Potência. A Vontade de Potência tem seu registro direto ao nível da práxis como expressão ${ }^{\mathbf{2 0}}$, como singularidade das formas de vida. Nietzsche faz um acréscimo de ordem ontológica, irônico, porém de

18 "De fato, já quando era um garoto de treze anos me perseguia o problema da origem do bem e do mal: a ele dediquei, numa idade em que se tem 'o coração dividido entre brinquedos e Deus', minha primeira brincadeira literária, meu primeiro exercício filosófico — quanto à 'solução' que encontrei então, bem, rendi homenagem a Deus, como é justo, fazendo-o Pai do mal. Era isso o que exigia meu 'a priori' de mim? Aquele novo e imoral, pelo menos imoralista 'a priori', e o 'imperativo categórico' que nele falava, tão antikantiano, tão enigmático, ao qual desde então tenho dado atenção, e mais que atenção?... Por fortuna logo aprendi a separar o preconceito teológico do moral, e não mais busquei a origem do mal por trás do mundo." (GM/GM, "Prólogo", 3, KSA 5.249).

19 Schacht, 1973, p. 76.

20 "Nietzsche escreve que todos os 'fins', 'metas', 'sentidos' são apenas maneiras de expressão e metamorfoses de uma vontade, inerente a todo acontecer: a vontade de potência... e que o mais universal e profundo instinto em todo fazer e querer permaneceu o mais desconhecido e oculto, porque in praxi nós sempre seguimos seu mandamento, porque nós somos esse mandamento" (Müller-Lauter, 1997, p. 92).

174 | Cad. Nietzsche, Guarulhos/Porto Seguro, v.39, n.2, p. 161-186, maio/agosto, 2018. 
A Moralidade do Desenvolvimento: Notas para uma tipologia...

suma importância: "Pois esta é a doutrina pregada pela própria vida a tudo o que tem vida: a moralidade do desenvolvimento. Para ter e querer mais - em uma palavra, crescimento - esta é a própria vida" (Nachlass/FP, 37[11], 1885, KSA 11.586).

\section{O filocrata nietzschiano}

No aforismo 211 de JGB/BM, citado acima, Nietzsche sugere o reino do político como o reino da moral, isto é, tudo o que até então se pensou a respeito da política esteve exclusivamente identificado à moral. Ou, de modo mais abrangente, toda ação política, inclusive a ação do pensamento político, é reflexo de uma moral e exprime um corpo de valorações, isto é, um conjunto de valores que são afirmados por determinado corpo social. Entretanto, esses valores não são eternos e, mais cedo ou mais tarde, "um mais forte dominará o forte" (JGB/BM, 241, KSA 5.180). Deduz-se daí que o campo do político é também o campo da moral, e qualquer avaliação da prática política, bem como de seus efeitos, deve investigar a moralidade. Logo, nenhum valor, nem moral nem político, pode ser considerado um valor objetivo. $\mathrm{O}$ temor de que males ocorram e de que bens futuros não se concretizem imprime nos grupamentos humanos um caráter irremediavelmente reativo, e os impele a reificar práticas e hábitos já codificados pela comunidade. A sanha da "pequena política" busca o poder como forma de perpetuar e atualizar uma determinada perspectiva moral, geralmente uma lembrança muito particular que, vinculada aos interesses econômicos, se articulam para gerar um contexto de guerras, disputas comerciais e falsos vereditos. A relação entre a moral e o acontecimento é sempre uma relação de reconhecimento. Não se pode maquinar positivamente o presente, fazê-lo emergir enquanto transvaloração de todos os valores, se as lentes grossas dos valores vigentes executam uma leitura acrítica em relação a seus preconceitos morais. É esse o desafio que Nietzsche 
Oliveira, B.

nos faz: como maquinar positivamente o presente, se nascemos e somos criados inseridos num sistema de formação absolutamente tomado pelo respeito aos "valores superiores"?

$\mathrm{O}$ contra-discurso nietzschiano se dirige à moderna cultura ocidental e reflete uma preocupação quanto ao futuro do tipohomem. Será digno desta "alta cultura" que Nietzsche enuncia? Como se livrará do caráter tutelar do estado, do processo de domesticação, do nivelamento dos desejos e das necessidades, do consumo como fator absoluto? A questão para Nietzsche reside no âmbito da existência, mais precisamente acerca das possibilidades de cultivo prolongado e contínuo de outras formas de vida mais expressivas que as experimentadas em contexto sociais religiosos e mercantilistas. Produzir uma "cultura afirmativa" corresponde a criar as condições para formas de vida independentes de todas as formas do incondicionado, sejam religiosas, metafísicas ou políticas. Assim, o filocrata nietzschiano é também um educador, embora o conteúdo que ensine não se apresente sob a forma de uma "revelação". Ao contrário, encoraja o educando a engajar-se em vertiginosos processos de auto-formação e experimentação, com vistas a apropriar-se de sua própria trajetória, constituindo-se com toda a potência que lhe é cabida. Por outro lado, na medida em que não há no pensamento de Nietzsche nada que assegure o transcendentalismo normativo que caracteriza o pensamento moral de Kant, mesmo quando ele insiste negativamente sobre um tema, como política e religião por exemplo, não se quer dizer que ele necessariamente não tenha nada a dizer sobre esses assuntos. Aqui, a política e a religião nunca são observadas de um ponto de vista estritamente conceitual, de modo que a crítica nietzschiana sempre se realiza a partir de observação e interpretação da expressão das formas de vida efetivamente constatadas, isto é, através da sua crítica da Cultura.

$\mathrm{O}$ que Nietzsche entende por cultura, quais as condições da "grandeza cultural"? Nietzsche utiliza a palavra cultura de forma 
A Moralidade do Desenvolvimento: Notas para uma tipologia...

polissêmica, no singular e no plural e, não raro, aborda o tema sem enunciá-lo. Por exemplo, quando deseja descrever um conjunto de processos, costumes e instituições específicos, dedicando-se a analisar contextos nacionais ou imperiais - a cultura alemã, a cultura francesa, a cultura grega etc. - ou comunitários e históricos: o cristianismo, o budismo, os anarquistas, os "psicólogos ingleses" e até mesmo contextos parciais, como a "cultura do sul da França" ou "cultura do norte da Alemanha", aproveitando-se das nuances que hábitos e costumes desses locais podem fornecer. Em alguns trechos podemos perceber que dois ou mais elementos convergem numa só questão de âmbito cultural, como a dominação cristã sobre a "cultura europeia", ou a contiguidade entre as influências do cristianismo, do platonismo e da democracia sobre a mesma cultura. Por vezes, entra em cena a "contradição" dos termos, por exemplo, quando Nietzsche afirma que o Estado é sintoma de uma doença cultural, e, por outro lado, que Cultura e Estado são antagonistas (GD/CI, "O que falta aos alemães", 4, KSA 6.106). Nietzsche também investe em uma tipologia geral da cultura, a cultura superior ("nobre", "afirmativa", "legisladora") e uma cultura inferior ("escrava", "negativa", "obediente"), descrita e aplicada em muitos momentos de sua obra. Outro emprego curioso da mesma palavra corresponde à sua situação no tempo: ora Nietzsche se refere às culturas do passado, ora a uma descontinuidade entre culturas nobres e escravas (MA I/HH I, 236, KSA 2.197), e, ainda, a uma inferiorização da cultura moderna em relação à cultura grega e ao Renascimento. Tal como a trama de perspectivas políticas, a cultura se afigura de uma forma também plural e multifacetada em seus escritos, preocupação sintonizada com o turbulento excerto a seguir:

Moral privada e moral mundial. — (...) A antiga moral, notadamente a de Kant, exige do indivíduo ações que se deseja serem de todos os homens: o que é algo belo e ingênuo; como se cada qual soubesse, sem dificuldades, que procedimento beneficiaria toda a humanidade (...). Talvez 
Oliveira, B.

uma futura visão geral das necessidades da humanidade mostre que não é absolutamente desejável que todos os homens ajam do mesmo modo, mas sim que, no interesse de objetivos ecumênicos, deveriam ser propostas, para segmentos inteiros da humanidade, tarefas especiais e talvez más, ocasionalmente. - Em todo caso, para que a humanidade não se destrua com um tal governo global consciente, deve-se antes obter, como critério científico para objetivos ecumênicos, um conhecimento das condições $d a$ cultura que até agora não foi atingido. Esta é a imensa tarefa dos grandes espíritos do próximo século (MA I/HH I, 25, KSA 2.46).

A tensão se estabelece entre a sondagem de um passado inescrutável e o horizonte de expectativa sobre o qual o filósofo projeta sua perspectiva. Nietzsche afirma a necessidade de um conhecimento das condições da cultura, conhecimento que permitiria aos indivíduos escapar do nivelamento da política moderna e viver segundo regras próprias e imanentes à sua própria capacidade de transfiguração e criação. Contudo, como conciliar uma cultura que depende da ação individual e, por outro lado, carece de objetivos ecumênicos? Como os homens poderão estabelecer para si os seus próprios valores e, ao mesmo tempo, projetarem um governo para a terra inteira? Em meio aos momentos em que ensaia os "prolegômenos" para uma afirmação da "grandeza cultural", Nietzsche determina uma diferenciação que marcará decisivamente sua concepção de cultura:

Os ápices da cultura e da civilização estão separados entre si: não devemos nos deixar extraviar sobre o abissal antagonismo entre cultura e civilização. Moralmente falando, os grandes momentos da cultura sempre foram tempos de corrupção, e, novamente, as épocas da voluntária e coerciva domação animal ("civilização") do homem foram tempos de intolerância para as naturezas mais espirituais e ousadas. A civilização quer outra coisa que a cultura quer: talvez algo inverso... (Nachlass/FP, 16 [10), 1888-1889, KSA 13.485)

Enquanto a civilização promove a petrificação da cultura, a cultura opera o elemento dinâmico dos grupamentos humanos.

178 | Cad. Nietzsche, Guarulhos/Porto Seguro, v.39, n.2, p. 161-186, maio/agosto, 2018. 
A Moralidade do Desenvolvimento: Notas para uma tipologia...

Nietzsche havia previsto esta dinâmica rarefeita no escrito inacabado "Sobre o futuro de nossos estabelecimentos de ensino", quando afirma que estas duas tendências se digladiam no seio da modernidade com prejuízos irreversíveis para a cultura. A civilização ("Zivilisation") remete à "domação animal", isto é, ao ordenamento civilizatório dos grupamentos humanos, a manutenção de uma dinâmica regulatória em vistas da supressão do comportamento e do pensamento anômalo. Neste caso, privilegia-se a estabilidade interna em favor da segurança da comunidade. Para Nietzsche, a civilização se constitui pela manutenção, contenção, controle em favor do estabelecimento de espaços de domínio, onde vigoram o poder daquela comunidade. E, no entanto, sobre a cultura, Nietzsche é por vezes evocativo: recorre novamente ao elogio de "naturezas mais espirituais e ousadas", porém acrescenta que, "moralmente falando", os momentos de grande cultura são momentos de corrupção. Enquanto a "civilização" pressupõe, assim como a tipologia moral kantiana, uma tábua de verdades a ser reiterada diária e voluntariamente, operando meios pelos quais a moral é como que cristalizada no próprio exercício da obediência, a cultura é "corrupção" desta obediência, é um atributo das "naturezas mais espirituais e ousadas", que fogem ao escopo do projeto civilizatório. Portanto, regularidade, previsibilidade e outros atributos diretamente relacionados à manutenção da "civilização" não constituem qualidades da cultura e de seus agentes, visto que ela comporta até mesmo a "corrupção" dos valores. A civilização busca a cristalização e a manutenção dos valores, ao passo que a cultura se afigura como uma espécie de esforço contrário, algo que permanece subscrito à imprevisibilidade da ação do "grande homem" e de sua repercussão na comunidade.

Para Nietzsche, a força individual do caráter é escopo e alimento da cultura; sua tarefa é promover a grandeza entre os homens. A cultura, portanto, é, por ora, alimenta da pela promoção do tipodominador, da exceção, elemento desestabilizador da obediência. Isso 
Oliveira, B.

nos obriga a fixar duas características da cultura segundo Nietzsche. Em primeiro lugar, tendo por agente o "grande homem", ela é o elemento dinâmico da comunidade — e, em última instância, da vida —, que promove a transformação dos valores através da afirmação dos casos específicos e da repercussão de suas ações na dinâmica valorativa da comunidade — de forma que caberia à política a promoção desses casos. Mas, ao mesmo tempo, na medida em que inocula o germe da transfiguração na comunidade, o "grande homem" também promove a vinculação entre o indivíduo e a coletividade, entre o singular e o universal, pois sua ação entranha-se de forma também diversa na economia espiritual da comunidade. Afinal,

(...) até mesmo $o$ ato individual de um grande homem não possui grandeza quando é infrutífero e sem ressonância; pois no instante de sua realização lhe faltou a visão profunda de sua necessidade: não mirou com a devida precisão, não identificou e escolheu o momento com a devida determinação, o acaso se tornou mais forte, ao passo que existe uma estreita relação entre ser grande e ter o sentido da necessidade (WB/Co. Ext. IV, 1, KSA 1.431).

Cabe então considerar a possibilidade de que Nietzsche coloque em perspectiva a grandeza individual do tipo-dominador, relacionando-a de forma intrínseca com o "sentido de necessidade" de uma comunidade. O portador da "grandeza", o indivíduo capaz de desestabilizar o nivelamento cultural que é produzido pela generalização da política moderna, como que incorpora as forças plásticas e criadoras da natureza, supera os constrangimentos do niilismo e intervém na composição moral, isto é, no conjunto de valores e experiências que dá sentido à vida de uma comunidade. Por este motivo, pelo caráter singular com que se define uma "cultura", pode-se afirmar com Nietzsche que: "Cultura é, antes de tudo, unidade de estilo em todas as expressões da vida de um povo" (DS/Co. Ext. I, 1, KSA 1.159). Antes de constituir os bens materiais e técnicas de manutenção ordenadoras da civilização, a cultura é a expressão de uma obra de arte coletiva.

$180 \mid$ Cad. Nietzsche, Guarulhos/Porto Seguro, v.39, n.2, p. 161-186, maio/agosto, 2018. 
A Moralidade do Desenvolvimento: Notas para uma tipologia...

\section{A transfiguração do niilismo}

Kant e Hegel conceberam o Estado no horizonte da articulação entre a sociedade e 0 aparelho jurídico-institucional, mas resguardaram sua importância como um "mal necessário". Em correlação direta com essa concepção, fizeram da virtude (e, em certa medida, do pensamento) uma instância policial, desprovida de caráter, nem expressão. ${ }^{21}$ Nietzsche não resguarda nenhum elemento caro à estabilidade do programa moderno, mas propõe uma crítica total. Somente ações efetivamente criadoras, que sejam capazes de transfigurar o espectro do niilismo em favor da cultura, podem reconfigurar as relações entre os diversos grupamentos humanos em escala planetária. Nesse sentido, quais seriam as contribuições efetivas de Nietzsche para o debate político contemporâneo? Por um lado, fazer a crítica dos dispositivos de controle que administram a comunidade como animais ou autômatos, construindo uma tipologia do domínio. De outro, evitar a personalização do tipo-dominador, ressaltando a necessidade comunitária de seu ato. Como horizonte desse desafio, Nietzsche antevê o sombrio espectro do niilismo na administração evanescente da "pequena política". Se o caráter prescritivo da filosofia política de inspiração hobbesiana e rousseauniana, mas também kantiana, trata de circunscrever o comportamento de modo a delinear uma conduta mínima ${ }^{22}$, é porque há a necessidade objetiva dos governantes de promoverem uma política calcada na estabilidade social, contra a

21 Sobre o estatuto "policial" da crítica kantiana, conferir o próprio Kant na segunda introdução à CRP: "Contestar a utilidade positiva deste serviço prestado pela Crítica equivaleria a dizer que a polícia não possui nenhuma utilidade positiva por ser sua principal ocupação fechar a porta à violência, que os cidadãos possam temer uns dos outros, para que cada um possa tratar tranqüila e seguramente dos seus interesses." (Kant, 1980, p. 15).

22 Neste aspecto, é notória a ligação entre o pensamento de Nietzsche com o de outros dois autores: Maquiavel e Espinosa. Maquiavel e a verità effetuale, a tomar sua própria experiência efetiva no trato com o poder como parâmetro para a reflexão; Espinosa e sua análise dos afetos, descrita na parte III da Ética, classificando o comportamento humano segundo critérios imanentes à prática efetiva. O que parece unir os três autores, embora em contextos diferentes, é a recusa absoluta de uma finalidade ontológica da existência. (Cf. Calvetti, 1972.)

Cad. Nietzsche, Guarulhos/Porto Seguro, v.39, n.2, p. 161-186, maio/agosto, 2018. 
Oliveira, B.

qual Nietzsche se voltará por ver nela um mal para a educação dos espíritos fortes e afirmativos. Neste sentido, o trabalho e a meta da cultura seriam o de promover "o caso único", isto é, criar condições para o advento do indivíduo que projetará o futuro e os valores que superarão o cristianismo e reverterão o niilismo. É neste horizonte conturbado, repleto de antagonismos, que emerge a figura do filocrata nietzschiano.

Estabelecendo algumas características da "grande política" da cultura em Nietzsche, podemos perceber que ela não se fia pela segurança e pela autoridade, mas elogia a instabilidade, o perigo e a má experiência como fontes de sabedoria e crescimento. Uma política em Nietzsche não demoniza o desconhecido e o estrangeiro, não é "nacional". Ao contrário: se há a possibilidade de isolarmos aspectos políticos do pensamento nietzschiano, este pensamento é fundamentalmente supra-nacional, cosmopolita, "europeu" 23, pois, como ele escreve "eu trago a guerra, mas não entre povos" (Nachlass/FP, 25 [1], 1888-1889, KSA 13.637). Por fim, uma política em Nietzsche não se pautaria em nenhuma espécie de contrato ${ }^{\mathbf{2 4}}$, nenhuma sorte de ilusão que converta as múltiplas condições da cultura a uma obrigação moral unívoca, para fins de controle policial e supressão da violência em comunidade. Pois se o cultivo individual é o único meio pelo qual podemos transformar as formas de vida - o que constitui uma objeção frontal às formas de representação política - então o desenvolvimento da cultura requer dos grandes indivíduos uma grande capacidade individual de experimentação, vivência [Erlebnis $]^{25}$ e auto-formação. O que, por outro lado, torna

23 Cf. FW/GC, 377, KSA 3.628: "Nós, os sem-pátria”.

24 Cf. GM/GM, II, 17, KSA 5.288 : "Quem pode dar ordens, quem por natureza é "senhor", quem é violento em atos e gestos - que tem a ver com contratos?"

25 Sobre o significado de Erlebnis ("experiência" ou "vivência") no pensamento de Nietzsche: "O uso geral da palavra Erlebnis originalmente possui três aspectos principais: 1) vivência tem o caráter de ligação imediata com a vida (Unmittelbarkeit), de modo que não se vivencia algo através do legado de uma tradição e nem através de algo de que "se ouviu falar", mas sim Erlebnis "é sempre vivenciada

182 | Cad. Nietzsche, Guarulhos/Porto Seguro, v.39, n.2, p. 161-186, maio/agosto, 2018. 
A Moralidade do Desenvolvimento: Notas para uma tipologia...

imprevisível a qualidade e o grau de necessidade de sua ação, de forma que ela não pode ser medida ou mesmo concebida segundo os limites impostos por um contrato fictício. Este panorama, podese perceber, diverge radicalmente da contribuição moderna particularmente, kantiana — para o debate político, abrindo espaço para uma filocracia pautada não na obediência a princípios, mas na possibilidade de criação de valores e transfiguração do niilismo.

por um Si" efetivamente, "cujo conteúdo não se deve a nenhuma construção", por isso o caráter de "imediatez" da vivência com a vida. 2) Além disso, o que é vivenciado deve ter uma intensidade de tal modo significativa, cujo resultado confere uma importância que transforma por completo o contexto geral da existência: "Ao mesmo tempo, a forma "o que se vivenciou" classifica o que, no curso da vivência imediata, ganhou duração e significabilidade para o todo de um contexto de vida, enquanto seu produto mediato" Que alguém ainda tenha que vivenciar algo significa não apenas que esse alguém estará ligado à vida de forma imediata, mas também que a vivência deve ter uma tal significabilidade, a ponto de conferir importância decisiva ao caráter global da vida daquele que vivencia." (Viesenteiner, 2013, p. 141-155) 
Oliveira, B.

\begin{abstract}
Insofar as that morality is established from the recognition of universal conditions for the general welfare, the "kantian philocrat" is distinguished by the impersonality of his actions, by obedience to the norm and the internalization of the responsibility in order to favoring "reason" and "universality" as regulative principles of actions and values. Considering nihilism as "disease of the will", the Nietzschean dominator-type should instead affirm the unique features of his personality. On overcoming the reactive nihilism, the dominator's typology in Nietzsche dictates another philocrat possibility, unpredictable and non-normative.

Keywords: Nietzsche, Kant, Typology, Morals
\end{abstract}

\title{
Rerefências Bibliográficas
}

CALVETTI, Carla Gallicet. Spinoza lettore del Machiavelli. Milão. Università Cattolica del Sacro Cuore, 1972.

CÂNDIDO, Antônio. “O portador." In Os pensadores — Nietzsche. São Paulo. Editora Abril. 1983.

CHAVES, Ernani. "Cultura e política: o jovem Nietzsche e Jakob Burckhardt". São Paulo. In: Cadernos Nietzsche 09: 41-66. 2000.

DENAT, C. \&WOTLING, P. Dictionnaire Nietzsche. Paris: Ellipses, 2013.

KANT, Immanuel. Fundamentação da metafísica dos costumes. In: Os pensadores

— Kant. São Paulo: Editora Abril. 1974.

. Crítica da Razão Pura. In: Os pensadores — Kant. São Paulo: Editora Abril. 1974.

KERSTING, W. "Politics, Freedom, and Order: Kant's Political Philosophy". Cambridge Companion to Kant. Ed. Paul Guyer. Ed. Cambridge University Press, 1992, pp. 342-366.

MÜLLER-LAUTER, Wolfgang. A doutrina da vontade de poder em Nietzsche. São Paulo: Annablume, 1997.

NIETZSCHE, F. Sämtliche Werke. Kritische Studienausgabe. G. Colli. e M. Montinari. Berlin: Walter de Gruyter, 1980.

184 | Cad. Nietzsche, Guarulhos/Porto Seguro, v.39, n.2, p. 161-186, maio/agosto, 2018. 
A Moralidade do Desenvolvimento: Notas para uma tipologia...

.Aurora. Trad. Paulo César de Souza. São Paulo: Companhia das Letras, 2004.

. Ecce homo - como alguém se torna o que é. Trad. Paulo César de Souza. São Paulo: Companhia das Letras, 2001.

- A Gaia Ciência. Trad. Paulo César de Souza. São Paulo: Companhia das Letras, 2002.

. Genealogia da moral. Trad. Paulo César de Souza. São Paulo. Companhia das Letras. 1998.

. O caso Wagner/Nietzsche contra Wagner. Trad. Paulo César de Souza. São Paulo. Companhia das Letras. 1999.

. Humano, demasiado humano. Trad. Paulo César de Souza. São Paulo. Companhia das Letras. 2000.

. Crepúsculo dos ídolos. Trad. Paulo César de Souza. São Paulo: Companhia das Letras, 2006.

. Além do bem e do mal - Um livro para espíritos livres. São Paulo: Companhia das Letras, 1992.

. O Anticristo. São Paulo: Companhia das Letras, 2007.

. "Schopenhauer educador" in Escritos sobre a educação. São Paulo: Edições Loyola, 2003.

. Wagner em Bayreuth. Quarta consideração extemporânea. Introdução, tradução e notas: Anna Hartmann Cavalcanti. Rio de Janeiro: Zahar, 2009.

PATON, H.J. The Categorial Imperative: A Study in Kant's Moral Philosophy. Publisher, Hutchinson's University Library, 1953.

REGINSTER, Bernard. The affirmation of life - Nietzsche on overcoming nihilism. Boston: Harvard University Press, 2006.

SCHACHT, Richard. "Nietzsche and Nihilism". In: R. Solomon, ed., Nietzsche: A Collection of Critical Essays. South Bend: University of Notre Dame Press, 1973, 58-82. 
Oliveira, B.

TONGEREN, Paul van. A Moral da Crítica de Nietzsche à Moral: Estudos sobre Para Além de Bem e Mal. Curitiba: Champagnat, 2012.

VIESENTEINER, Jorge. "O Conceito de Vivência (Erlebnis) em Nietzsche: Gênese, Significado e Recepção.” Revista Kriterion, Belo Horizonte, n. 127/2013, pp. 141-155.

Artigo recebido para publicação em 02/08/2017 Artigo aceito para publicação em 10/07/2018

186 | Cad. Nietzsche, Guarulhos/Porto Seguro, v.39, n.2, p. 161-186, maio/agosto, 2018. 